\title{
Aggression Behaviour and Physical Fitness of National Handball Girls Players
}

\author{
Gangu Naidu Mandala*, Kavitha Desai, Jerlin Jose, Nilofer Hussaini, Martha Sucharitha M \\ Department of Professional Studies, CHRIST Deemed to be University, Bengaluru, India
}

Received February 9, 2021; Revised July 26, 2021; Accepted August 2, 2021

\section{Cite This Paper in the following Citation Styles}

(a): [1] Gangu Naidu Mandala, Kavitha Desai, Jerlin Jose, Nilofer Hussaini, Martha Sucharitha M , "Aggression Behaviour and Physical Fitness of National Handball Girls Players," International Journal of Human Movement and Sports Sciences, Vol. 10, No. 1, pp. 1 - 5, 2022. DOI: 10.13189/saj.2022.100101.

(b): Gangu Naidu Mandala, Kavitha Desai, Jerlin Jose, Nilofer Hussaini, Martha Sucharitha M (2022). Aggression Behaviour and Physical Fitness of National Handball Girls Players. International Journal of Human Movement and Sports Sciences, 10(1), 1 - 5. DOI: 10.13189/saj.2022.100101.

Copyright $\subseteq 2022$ by authors, all rights reserved. Authors agree that this article remains permanently open access under the terms of the Creative Commons Attribution License 4.0 International License

\begin{abstract}
Aggression is one of the significant types of feeling and emotion, which is exceptionally fundamental for sports execution. It is ordinarily propelled conduct at any rate for that specific purpose of time in the genuine play, which drives a player brimming with his energies towards his point. 150 School National Handball female players aged 14-17 years who were concentrated in higher optional schools of Andhra Pradesh Rural and Urban were haphazardly chosen as subjects. An aggression scale is used to contemplate the degree of aggression in any age gathering (over 14 years). The scale comprises 55 articulations. It is a Likert type 5-guide scale toward locating the aggressive conduct among Handball players. The premise of the discoveries is that the shooters have phenomenal aggression conduct than the all-rounders and defenders and shooters have more physical fitness than the all-rounders and defenders. In the examination, the Shooter would have a more aggressive inclination and physical fitness when contrasted with all-rounders and defenders. It is very different on the grounds that the Shooter alone for example independently will confront the adversary gathering of players because of body contact and the battle for greatness will lead the shooter to more aggressive than others.
\end{abstract}

Keywords Aggressive Behaviour, Handball Players, Physical Fitness

\section{Introduction}

A greater degree of aggressiveness and physical fitness was shown in the research among raiders compared to all-rounders and defenders. As a result of physical contact, raiders will face off against the opposing group of players one-on-one, and the desire to be the best will motivate raiders to be more aggressive than their opponents. On the basis of the results, the study indicates that raiders exhibit better aggressiveness than all-rounders and defenders, and that raiders possess more physical fitness than all-rounders and defenders.

Handball is played on a rectangular court of $40 \times 20$ meters. The goals at each end are limited by an objective zone line of 6 meters, generally cut, and in which just the group's goalkeeper can act [1]. A player is permitted to hold the ball for as long as 3 seconds, to move to hold the ball for a limit of 3 stages, and to spill until being halted. The defender may battle for ownership of the ball and keep the adversary from taking shots at the objective as long as the player doesn't get, push or in any case imperil the rival's physical trustworthiness.

Direct observation of players' practices during games shows that players' responses to rivals' aggression broadly contrast from one player to the next. A few players appear to have the option to apply solid discretion; they never fight back during the occasion, even in serious cases [2]. As Robbie Fowler showed in 1997, they really typify sportsmanship. They, in any case, may plainly communicate their resentment at the awful adversary. 
Conversely, different players promptly respond to the primary aggressive act. They will be in general act naturally focused, and therefore, their responses appear to be to a great extent driven by their immediate rival's incitements [3]. Like Joey Barton, they now and again will in general carry on as though aggression was essential for the play. Different players receive center-ground practices. They don't promptly respond to the principal attack, yet they don't stop for a second to fight back in the event of recharged breaks [4]. They embrace what has been known as a 'tit for two tats' procedure [5]. These perceptions are steady with the possibility that, subjectively, various types of feeling guideline systems exist among individuals, going from under-guideline to over-regulation and including multipurpose guidelines. The current examination analyzed whether it was conceivable to discover, with regard to games, extra observational help for these subjectively various approaches to respond to aggression [6]. Handball playing was picked on the grounds that it includes a ton of physical/social cooperation in which players can be exposed to various types of aggression. A situation procedure that has just been actualized in investigations explicitly pointed toward planning individuals' mentalities in assorted spaces [7]. Four variables, acquired from the writing on aggression in-game, were considered in the situations: (a) the number and sort of past aggressive acts that have influenced the player; (b) the current group's score; (c) the mentor's disposition to aggression; and (d) the danger of being authorized.

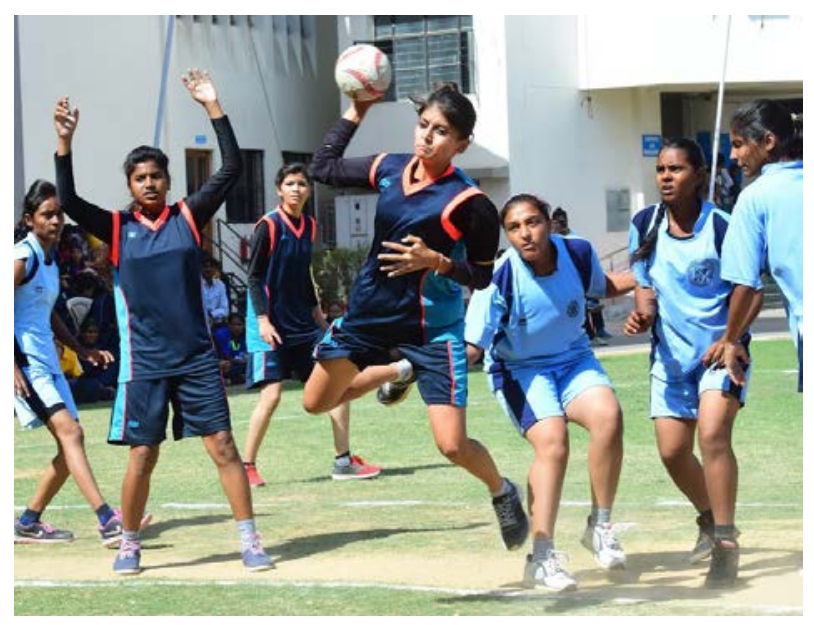

Figure 1. National Handball girl players

It is well known that one's body size has an impact on one's ability to perform physically. Taller people would be more effective at occupations that need a great deal of strength. Nonthrowing athletes have a tendency to be shorter, heavier, and less muscularly developed than throwers. When it comes to throwing ability and isometric strength, the size of your body has a big impact on your results.
Handball is an intermittent team sport that demands major physiological characteristics, such as an aerobic profile, in order to perform well. A high level of aerobic capacity appears to be required in order to maintain a high level of performance over the 30-minute playing time span.

\section{Review of Literature}

A refreshed injury reconnaissance of youthful handball players is required due to the expanded danger of injury in late handball match-ups with expanded force [8]. This examination analyzed intense wounds in youthful handball players during games. Conversely, the injury was the primary driver of injury in goalkeepers, trailed by the injury on the head/face. Ends: Preventive estimates focusing on hyper-extends in the lower the furthest point and improved ability in ball-dealing with method ought to be considered to forestall head/face and wrist/hand wounds, particularly in young men.

Overuse shoulder wounds are normal in youth handball, however, research is restricted [9]. The motivation behind this investigation was to distinguish pre-season hazard factors related to abuse shoulder wounds in this populace. Cantered pre-season appraisals may help the recognizable proof of danger factors for shoulder abuse wounds and the utilization of explicit projects to diminish hazard.

The reason for this exploration was to examine the psychophysiological condition of female handball players with various game jobs [10]. This exploration was done based on the lesser group of Ukraine, including the investment of 34 girls aged 15-16 years. The accompanying exploration techniques were utilized to accomplish this objective: The Luscher shading test, the appraisal of the condition of aerodynamic capacities (balance and utilitarian portability of the anxious cycles), Raven's intellectual test, and the assessment of practical cerebrum imbalance. The examination led uncovered the presence of solid contrasts $i$ the pointers of psychophysiological states among female handball players of various jobs (straight, semi-medium, outrageous players). The assessments of the psycho physiological state and the degree of general working, just as the utilitarian portability and equilibrium of nerve measures between players of various game jobs, are showed dependable contrasts. This reality may vouch for a critical contrast in the sign of hereditary acquired practical qualities. It has been set up that high proficiency and speed of visual data preparing are seen in extraordinary players, undeniable degree of stress in straight players, and a significant degree of nonverbal insight in the semi-medium players.

Sports can now and again turn into a negative mingling specialist for competitors [11]. The targets here were to investigate the connection between persuasive environments (including mentors and companions) and 
dread of disappointment in players as indicated by sexual orientation and sports insight, and furthermore to control for the degree to which these inspirational environments foresee the diverse aversive reasons because of a paranoid fear of disappointment. To this point, a non-trial, graphic, and sectional plan was utilized in which members addressed the Perceived Motivational Climate in Sport Questionnaire, the Peer Motivational Climate in Youth Sports Questionnaire, and the Performance Failure Appraisal Inventory. The example included 479 handball players who aged 16-17 years of age (mean $=16.60$; standard deviation $=0.50$ ) who were playing in Spanish local youth classification handball crews. The outcomes uncovered that the assignment including preparing environment prevails in the two sexes over the self-image including preparing the environment, especially in girls and in less experienced players. The companion sense of self including environment likewise prevails regarding the friend task including the environment in the two sexes, yet this is especially so for young men and in more experienced players. Moreover, aside from the dread of feeling disgrace, which was anticipated by the companion's sense of self including the environment, every one of the aversive reasons inspired by a paranoid fear of disappointment is anticipated fundamentally by the training environment. The prompt climate ended up being determinant in shirking practices and dread of disappointment.

\section{Objectives}

1. To analyze the all-rounder and defender National Handball girl players' aggressive behavior

2. To study the physical fitness of all-rounder $\&$ defender and all-rounder \& Shooter National Handball girl players.

\section{Hypothesis}

H1: There is no significant mean difference in all-rounder and defender National Handball girl players' aggressive behavior

H2: There were no significant mean differences in physical fitness of all-rounder $\&$ defender and all-rounder
\& Shooter National Handball girl players.

\section{Research Methodology}

A greater degree of aggressiveness and physical fitness was shown in the research among raiders compared to all-rounders and defenders. As a result of physical contact, raiders will face off against the opposing group of players one-on-one, and the desire to be the best will motivate raiders to be more aggressive than their opponents. On the basis of the results, the study indicates that raiders exhibit better aggressiveness than all-rounders and defenders, and that raiders possess more physical fitness than all-rounders and defenders.

In scientific investigations, statistical tools can be employed to count and evaluate the participants' responses. If the test is being carried out in accordance with a predetermined aspect, we carry out a thorough assessment of the results (a classic complete observation is the census). In cases where the observation only covers a small number of individuals from the population, we undertake a partial observation. The importance of representative observations in partial observations cannot be overstated. In the case of a partial (and especially representative) observation, we do not have information on all of the individuals in the full population; instead, we attempt to make approximation statements about the population based on the sample. We can immediately see that the inference will be successful only if the sample used is representative of the entire population, which is clearly demonstrated.

Primary data: An aggression scale is utilized to examine the degree of aggression in any age gathering (over 14 years). The scale comprises 55 proclamations. It is Likert type 5-guide scale toward locating the aggressive conduct among Handball players.

The sample is and size: 150 School National Handball female players aged 14-18 years who were concentrated in higher auxiliary schools of Andhra Pradesh Rural and Urban were arbitrarily chosen as subjects.

Statistical Tools: to examine the Aggression scale in this examination we have adjusted mean, Standard Deviation, and t-Test factual devices. 
Table 1. Aggression behaviour among raiders, defenders and all-rounder National Handball players (Girls)

\begin{tabular}{|c|c|c|c|c|c|}
\hline Variable & Play Position & Mean & S.D. & 't' value & Level of Significance \\
\hline \multirow{6}{*}{ Aggression } & All rounder & 198.555 & 26.305 & \multirow{2}{*}{1.301} & \multirow{2}{*}{ NS } \\
\hline & Defender & 186.300 & 18.402 & & \\
\hline & Defender & 186.300 & 18.402 & \multirow{2}{*}{3.413} & \multirow{2}{*}{$* *$} \\
\hline & Shooter & 222.755 & 34.005 & & \\
\hline & All rounder & 198.555 & 26.305 & \multirow{2}{*}{2.097} & \multirow{2}{*}{$*$} \\
\hline & Shooter & 222.755 & 35.005 & & \\
\hline
\end{tabular}

Sources: Primary data

Aggression is one of the most common emotions, and it's essential for sporting success. It is a typical motivated behaviour in which a player commits all of his energies to accomplishing his goal, at least at that exact stage in the actual game. Aggression in sports can be influenced by game rules (amount of physical contact), frustration, instinct, presence, arousal, contextual clues, self-control, and the behaviour of others. Personality, media exposure, coaching, role models, and the environment in which we live are all factors that contribute to violence.

Table 1 shows that there was a huge mean distinction in aggressive conduct among defender and shooter National Handball female players and furthermore presumed that mean scores of aggressive conduct of shooter $(\mathrm{M}=222.755)$ have more when contrasted and mean scores of aggressive conduct of defenders $(\mathrm{M}=186.300)$.

There was a huge mean contrast in aggressive conduct among all-rounder and Shooter National Handball young lady players and furthermore reasoned that aggressive conduct mean scores of Shooter $(\mathrm{M}=222.755)$ have more when contrasted and aggressive conduct mean scores of defenders ( $M=198.555)$

There was no critical mean distinction on the whole rounder and defender National Handball young lady players' aggressive conduct

Table 2. Table physical fitness among raiders, defenders and all-rounders National Kabaddi players (Girls)

\begin{tabular}{|c|c|c|c|c|c|}
\hline Variable & $\begin{array}{c}\text { Play } \\
\text { Position }\end{array}$ & Mean & S.D. & $\begin{array}{c}\text { 't' } \\
\text { value }\end{array}$ & $\begin{array}{c}\text { Level of } \\
\text { Significance }\end{array}$ \\
\hline \multirow{6}{*}{$\begin{array}{c}\text { Physical } \\
\text { Fitness }\end{array}$} & $\begin{array}{c}\text { All } \\
\text { rounder }\end{array}$ & 30.055 & 4.510 & \multirow{2}{*}{0.672} & \multirow{2}{*}{ N.S } \\
\hline & Defender & 28.700 & 4.118 & & \\
\hline & Defender & 28.700 & 4.118 & \multirow{2}{*}{2.062} & \multirow{2}{*}{$*$} \\
\hline & Raider & 32.001 & 4.114 & & \\
\hline & $\begin{array}{c}\text { All } \\
\text { rounder }\end{array}$ & 30.055 & 4.510 & \multirow{2}{*}{1.085} & \multirow{2}{*}{ N.S } \\
\hline & Raider & 32.001 & 4.114 & & \\
\hline
\end{tabular}

Sources: Primary data

Aggression is one of the most common emotions, and it's essential for sporting success. It is a typical motivated behavior in which a player commits all of his energies to accomplishing his goal, at least at that exact stage in the actual game. Aggression in sports can be influenced by game rules (amount of physical contact), frustration, instinct, presence, arousal, contextual clues, self-control, and the behaviour of others. Personality, media exposure, coaching, role models, and the environment in which we live are all factors that contribute to violence.

Table 2 shows that there was a critical mean contrast in physical fitness among defender and Shooter National Handball young lady players and furthermore inferred that physical fitness of looters (mean=32.001) have more mean scores when contrasted and physical fitness mean scores of defenders (mean $=28.700$ ).

There were no critical mean contrasts in physical fitness of all-rounder and defender and all-rounder and Shooter National Handball young lady players.

\section{Conclusions}

In the examination, the Shooter would have a more aggressive inclination and physical fitness when contrasted with all-rounders and defenders. It is very different on the grounds that the Shooter alone for example independently will confront the adversary gathering of players because of body contact and the battle for greatness will lead the Shooter to be more aggressive than others. It likewise the reason that based on the discoveries the Shooters have superb aggression conduct than the all-rounder's and defenders and Shooters have more physical fitness than the all-rounders and defenders. The premise of the discoveries the shooters have phenomenal aggression conduct than the all-rounder's and defenders and Shooters have more physical fitness than the all-rounders and defenders. In the examination, the Shooter would have a more aggressive inclination and physical fitness when contrasted with all-rounders and defenders. It is very different on the grounds that the Shooter alone for example independently will confront the adversary gathering of players because of body contact and the battle for greatness will lead the Shooter to more 
aggressive than others.

\section{REFERENCES}

[1] Trajkovi, N., Madic, D.M., Milanovic, Z., MacAk, D., Padulo, J., Krustrup, P., Chamari, K. Eight months of school-based soccer improves physical fitness and reduces aggression in high-school children, Biology of Sport, Volume 37, Issue 2, 31 March 2020, Pages 185-193

[2] Trajković, N., Pajek, M., Sporiš, G., Petrinović, L., Bogataj, $\mathrm{S}$, Reducing Aggression and Improving Physical Fitness in Adolescents Through an After-School Volleyball Program, Frontiers in Psychology, Volume 11, 12 August 2020, Article number 2081

[3] Batez, M, Petrušič, T, Bogataj, Š, Trajković, N, Effects of teaching program based on teaching games for understanding model on volleyball skills and enjoyment in secondary school students. Sustainability (Switzerland) Volume 13, Issue 2, 2 January 2021, Article number 606, Pages 1-7

[4] Bailasha N. K , Rintaugu E. G , Kamau J , Mwangi F. M , Mucheke C. M , Otieno M. D (2020). Institutional Based Reasons for Students Non-participation in Physical Activity and Sport Programs in the Kenyan Public Universities. International Journal of Human Movement and Sports Sciences, 8(1), 17 - 23. DOI: 10.13189/saj.2020.080102.

[5] Courtenay C. Stewart-Reiner (2020). The Psychological Parameters of Athletic Injuries in Female Collegiate Athletes. International Journal of Human Movement and Sports Sciences, 8(1), 32 - 36. DOI: 10.13189/saj.2020.080104.
[6] Tamer Karademir , Ökkes Alpaslan Gençay (2020). Psychological Resilience and Violence Tendency Levels of High School Adolescents Who Doing Team and Individual Sports. International Journal of Human Movement and Sports Sciences, 8(2), 69 - $78 . \quad$ DOI: 10.13189/saj.2020.080204.

[7] Karolina Kostorz , Krzysztof Sas-Nowosielski, Martial arts, combat sports, and self-determined motivation as predictors of aggressive tendencies, Journal of Physical Education and Sport ${ }^{\circledR}$ (JPES), Vol. 21 (1), Art 17, pp. 122 - 129, January 2021.

[8] Asai, K., Nakase, J., Shimozaki, K., Toyooka, K., Kitaoka, K., Tsuchiya, H. 2020 Incidence of injury in young handball players during national competition: A 6-year survey, Journal of Orthopaedic Science, Volume 25, Issue 4, July 2020, Pages 677-681.

[9] Achenbach, L. , Laver, L., Walter, S.S., Zeman, F., Kuhr, M., Krutsch, W, , Decreased external rotation strength is a risk factor for overuse shoulder injury in youth elite handball athletes, Knee Surgery, Sports Traumatology, Arthroscopy, Volume 28, Issue 4, 1 April 2020, Pages 1202-1211.

[10] Korobeynikov, G, Potop, V, Ion, M, Korobeynikova, L., Borisova, O, Tishchenko, V, Yarmak, O, Tolkunova, I, Mospan, M., Smoliar, I, Psychophysiological state of female handball players with different game roles, Journal of Physical Education and Sport Open Access, Volume 19, Issue 3, September 2019, Article number 248, Pages 1698-1702.

[11] Gómez-López, M, Ruiz-Sánchez, V, Granero-Gallegos, A, Analysis of the prediction of motivational climate in handball players' fear of failure, International Journal of Environmental Research and Public Health Open Access, Volume 16, Issue 3, 1 February 2019, Article number 344 